\title{
Nervous system Lyme disease
}

\author{
JJ Halperin \\ Medical Director, Atlantic Neuroscience Institute, Summit, New Jersey, and Professor of Neurology, Mount Sinai School of Medicine, \\ New York, USA
}

This review is based on a presentation given by Professor Halperin at the RCPE Infectious Diseases Symposium on II June 2010.

\begin{abstract}
Lyme disease, the multi-system infection caused by the tick-borne spirochaete Borrelia burgdorferi, can involve the nervous system, most commonly causing, alone or in combination, lymphocytic meningitis or abnormalities of cranial or peripheral nerves, the latter most typically presenting as a painful radicular syndrome. Diagnosis is based on appropriately used, standard serological tests; in instances where the central nervous system is involved, cerebrospinal fluid assessment for organism-specific antibodies can be useful. Treatment with any of several standard regimens of oral or parenteral antimicrobials is highly effective. Prolonged treatment beyond four weeks is rarely if ever warranted, and carries significant risk.
\end{abstract}

KEYWORDS Borrelia burgdorferi, diagnosis, Garin-Bujadoux-Bannwarth syndrome, Lyme disease, neuroborreliosis, treatment

DECLARATION OF INTERESTS No conflict of interests declared.
Correspondence to J Halperin, Department of Neurosciences, Overlook Hospital, 99 Beauvoir Avenue, Summit, New Jersey 07902, USA

tel. +19085223501

e-mail

john.halperin@atlantichealth.org

\section{BACKGROUND}

Although much has been learned about Lyme disease in the century since its typical cutaneous manifestation, erythema migrans, was first described,' this multisystem infection by the tick-borne spirochaete Borrelia burgdorferi continues to be the source of spirited debate. The classic neurological picture has been recognised for almost 90 years. ${ }^{2}$ The responsible organism was identified three decades ago., ${ }^{3,4}$ eliable diagnostic testing is available, and straightforward treatment regimens have been shown to be effective. ${ }^{5.6}$ Despite this, some continue to portray this infection as a great unknown, suggesting a role for it in a broad range of disorders - a role often neither supported by compelling evidence nor even biologically plausible. Many factors contribute to this paradox; most important is probably a fundamental misunderstanding of the nature of neurological disease in general and the neurological manifestations of this infection in particular.

To understand both the debate and the reality, it is helpful to appreciate the two key elements of this 'controversy' - first, the pathophysiology, diagnosis and treatment of Lyme disease and, second, what actually constitutes neurological disease. Sadly, neurological disease is simultaneously terrifying to patients and discomfiting if not intimidating to many practitioners. When clinicians mistakenly attribute non-specific symptoms to a brain infection, which in turn is believed by many to be difficult to treat, the stage is set for desperate patients to seek inappropriate treatment the essence of the current unfortunate 'debate'.

\section{AETIOLOGY}

The term 'Lyme disease' was coined in the 1970s when two mothers in Lyme, Connecticut, recognised that an inordinate number of children in their rural area were being diagnosed with juvenile rheumatoid arthritis. ${ }^{7}$ The resulting investigation by Steere and his colleagues led to the conclusion that this was a tick-borne infection, initially named Lyme arthritis, then, as its more disseminated elements were recognised, Lyme disease. This work ultimately led to the identification of the causative spirochaete, B. burgdorferi, first in ticks, then in humans. ${ }^{8.9}$

The characteristic rash, erythema migrans, was actually first reported in Scandinavia in 1910; the typical neurological triad was described in 1922 at which time the authors even conjectured it was due to a spirochaetal infection. By the 1940s it was recognised that patients could have rheumatological symptoms, ${ }^{10}$ and by the 1950 s penicillin was known to provide effective treatment." European work in the 1970s and 1980s ultimately led to the characterisation of the same group of causative spirochaetes. ${ }^{4}$

Subsequent extensive microbiological work led to the identification of four strains of what has come to be known as $B$. burgdorferi sensu lato: $B$. burgdorferi sensu stricto, B. afzelii, B. garinii and, most recently, B. spielmanii. Sensu stricto is the only strain identified in North America; all four occur in Europe, although B. garinii and B. afzelii predominate. Many argue that clinical phenomenology varies substantially between Europe and the US, attributing this to strain differences. Neglected in this discussion is the fact that, as a systemic 
disease, this infection was initially treated for years primarily by neurologists in Europe and rheumatologists in the US - leading to substantial potential for ascertainment bias in the clinical disorders identified with this infection.

Infection is transmitted virtually exclusively by the bites of hard-shelled Ixodes ticks - Ixodes scapularis and I. pacificus in the US, I. ricinus in Europe, I. persulcatus elsewhere. Although Borrelia have been identified in other blood-feeding arthropods, transmission of this zoonosis requires the specific feeding cycle of these ticks. Ixodes larvae hatch uninfected and feed once. If there is an available reservoir of infected hosts - most often field mice - and the tick feeds on one, the tick can become infected. Following this blood meal, the larva matures into a nymph. An infected nymph, the size of a full stop on a printed page, can then feed on a second host, potentially transmitting infection.

Transmission is not instantaneous. Both initially during attachment and subsequently during its several days of feeding, the tick injects local anaesthetics, anticoagulants and other compounds to allow it to feed undisturbed. Arrival of the host's blood in the tick gut triggers spirochaete proliferation, then migration throughout the tick, including to its salivary glands, from which spirochaetes can be injected into this second host. This process requires $24-48$ hours or more; hence only bites of more than a day or two's duration pose a significant risk of infection.

During feeding, ticks become visibly larger and engorged with blood. This provides a useful measure of risk of infection - if a removed tick is tiny and contains minimal blood, the risk of infection is virtually non-existent. If it is engorged from prolonged feeding, risk is increased though still relatively small. A recent meta-analysis ${ }^{12}$ suggests that treating tick bites - in high-risk areas with a single dose of doxycycline may be beneficial, although individual studies have indicated that the risk of infection is quite low, that when infection occurs treatment response is essentially $100 \%$ and that the risk of antibiotic side effects approximates the risk of becoming infected and requiring treatment. ${ }^{13}$

After its second meal, the tick matures into the larger adult. These too can transmit infection. However, their larger size makes them more noticeable and less of a risk since they can be noticed earlier in their feeding and removed. The adults tend to overwinter on large furry animals such as sheep (Europe), deer or bears (US), leading to the ticks' popular names.

Transmission to humans occurs when people enter endemic areas where lxodes ticks, reservoir hosts and B. borrelia all co-localise - a co-occurrence found only in specific environments, ${ }^{14}$ strongly influenced by local soil type, vegetation and climate. Even when ecological conditions permit the coexistence of ticks, Borrelia and reservoir hosts, an endemic focus can only exist when all three have been successfully introduced. Because ticks travel only short distances by themselves and field mice travel only slightly more, there is substantial variability in the proportion of ticks carrying $B$. burgdorferi, even in geographically adjacent areas. Expansion of endemic areas, such as has been noted in recent years, probably occurs primarily when larger hosts - birds, dogs, cats, raccoons, etc. - carry infected ticks to new areas. If the new areas are capable of supporting all elements of this zoonosis, a new endemic focus can be established. Some of the recent expansion of Lyme-endemic areas may have been facilitated by climate change, transforming areas previously too cold for the interacting life cycles into more hospitable environments.

If a sufficient number of spirochaetes is injected they will multiply at the site of the bite, then gradually migrate centrifugally. This leads to an enlarging erythroderm erythema migrans (EM).Typically round to oval, often with concentric rings as the inflammatory response to the spirochaetes subsides more centrally just as it is flaring up more peripherally, the defining characteristics of this rash are its large size (typically $>5 \mathrm{~cm}$ in diameter) and the fact that it enlarges day by day and persists for many days or weeks. The rash is often remarkably asymptomatic (reminiscent of the painless chancre of its cousin spirochaete, syphilis). Patients often have systemic symptoms reflecting the presence of a systemic bacterial infection. In the US, up to $15 \%$ or more of patients develop multifocal EM. Each secondary focus represents a nidus of spirochaetes that has metastasised from the primary site, lodged in the skin, and then gradually recapitulated the initial outward migration. This is one manifestation that appears to be less common in European patients.

The reported proportion of infected patients who develop EM varies widely. In children, whose parents are presumably more likely to observe the rash than patients themselves (particularly if in a difficult-to-see location), EM is thought to occur in about $90 \%$ of infected individuals. ${ }^{15}$

In theory the systemic dissemination of spirochaetes could involve any part of the body. However, in humans infection primarily involves three extra-cutaneous organ systems - the heart, most commonly causing otherwise unexplained conduction block; the joints, causing arthralgias or, typically much later in infection, frank arthritis; and the nervous system.

Studies using polymerase chain reaction (PCR) suggest the central nervous system can be seeded quite early and often; ${ }^{16}$ however, only $10-15 \%$ of patients ever develop symptomatic nervous system involvement. As will be detailed below, nervous system infection most 
commonly consists of cranial neuropathy, painful radiculopathy or lymphocytic meningitis.

\section{DIAGNOSIS}

Borrelia burgdorferi is difficult - but not impossible - to grow in culture. Since the required medium, BSK II, is not routinely available in most laboratories, and since cultures must be incubated at lower than usual temperatures and must be monitored for several weeks because of the organism's slow doubling time, microbiological-based diagnosis has been challenging at best. Even PCR-based detection has proven disappointing, probably because very few organisms are present in readily sampled fluids. As a result, much as in syphilis, diagnosis typically rests largely on demonstration of a targeted antibody response.

Just as in syphilis, at the onset, inspection of the cutaneous lesion provides definitive diagnosis. Like the chancre, EM contains innumerable spirochaetes; however, the rash is usually so characteristic that microbiological examination is generally unnecessary. Not surprisingly, since the rash occurs within days (typically $<30$ days) of initial inoculation of organisms, many patients with EM do not yet have a measurable antibody response. ${ }^{17}$ This is not due to any particular flaw in the immune system or the available test methodology but rather is the natural consequence of the time-requiring processes by which $B$ cells are selected, multiply and mature into antibody-producing cells, ultimately producing appropriately targeted immunoglobulin $\mathrm{G}(\mathrm{lgG})$ antibodies.

Some early studies ${ }^{18}$ suggested that partially treated patients might not develop measurable peripheral blood antibody responses. This observation has been difficult to reproduce with more modern techniques and is now widely thought to have been an artefact of the thenavailable technology.

Laboratory testing begins with a screening test ${ }^{19}$ - most commonly an enzyme-linked immunosorbent assay (ELISA), a measure of the total amount of antibody present in the patient's blood that binds to B. burgdorferi. If this is positive (three standard deviations above the mean of a control population) or borderline (between two and three standard deviations), a more specific test, the Western blot, is performed to identify the specific antigens (represented by bands on the blots) to which these antibodies bind. Importantly, since the criteria for interpreting Western blots were defined in individuals with positive or borderline ELISAs, blots are not informative - and should not be performed - in patients with negative ELISAs.

Western blot criteria differ in Europe and the US, largely because of the greater strain variability in Europe. In the US, ${ }^{19,20}$ statistical studies of large populations led to
TABLE I Western blot criteria for confirmation of positive or borderline ELISA in Lyme disease

\begin{tabular}{|c|c|c|}
\hline & $\lg M$ & IgG \\
\hline US' ${ }^{19}$ & $\begin{array}{l}\text { At least two of } \\
(4 I, 39,23)\end{array}$ & $\begin{array}{l}\text { At least five of }(93,66,58 \text {, } \\
45,41,39,30,28,23,18)\end{array}$ \\
\hline Germany $y^{21,23 *}$ & $\begin{array}{l}\text { B. afzelii: at least } \\
\text { one of }(39, \text { OspC } \\
\text { \& I7), or strong } 4 \text { I } \\
\text { B. garinii: at least } \\
\text { one of }(39, \text { OspC }) \\
\text { or strong } 41\end{array}$ & $\begin{array}{l}\text { B. afzelii: at least two of } \\
(\mathbf{8 3} / 1 \mathbf{0 0}, \mathbf{5 8}, 43,39,30, \\
\text { OspC, 2I, I7, I4) } \\
\text { B. garinii: at least one of } \\
(\mathbf{8 3} / 1 \mathbf{1 0 0}, 39,30, \text { OspC, } \\
21,17)\end{array}$ \\
\hline $\begin{array}{l}\text { Most other } \\
\text { European } \\
\text { countries }^{*}\end{array}$ & $\begin{array}{l}\text { At least two of } \\
(17,22[\text { OspC], } \\
39,41, \text { B. garinii } \\
\text { OspC) }\end{array}$ & $\begin{array}{l}\text { At least three of (14, } \\
\text { I7, 22 [OspC], 30, } 39 \text {, } \\
43,58,100, \text { B. garinii } \\
\text { OspC, BbVlsE) }\end{array}$ \\
\hline
\end{tabular}

Bands bolded felt to be particularly important in Germany.

"These patterns are specific for Trinity Biotech MarDx blot kits, widely used in Europe. Criteria differ with different kits in different countries; sensitivity and specificity vary among kits and depend on the specific criteria selected (personal communication, S O'Connell).

identification of three IgM bands (Table I) present in many infected patients. Presence of two of the three in a patient with symptoms of early disease and a positive or borderline ELISA has near $100 \%$ specificity, but somewhat lower sensitivity. The IgM reactivity becomes irrelevant in individuals with symptoms of more than one to two months' duration, as by then the IgG response should be measurable. Again, a statistical analysis led to the identification of ten bands; the presence of five of the ten in a patient with a positive or borderline ELISA indicates the presence of Lyme disease with near 100\% specificity and very high sensitivity.

In Europe, ${ }^{21-23}$ the approach has been to look for a smaller number of bands, each of which is thought to be quite specific to $B$. burgdorferi sensu lato. The presence of several of these in a seropositive patient provides compelling diagnostic confirmation (Table I). In both the US and Europe, a newer assay ${ }^{24,25}$ for the $\mathrm{C} 6$ peptide (VlsE) has drawn increasing attention. Although not perfect, the results of this single-peptide ELISA appear to compare favourably in sensitivity and specificity to the two-tier approach.

There are several key limitations to serological diagnosis. Not only does it take time for a directed immune response to become measurable, but, once developed, it persists long after successful eradication of the inciting cause - hence the ELISA does not provide a meaningful measure of disease activity or of treatment response.

One of the biggest challenges concerns the concept of any test's positive predictive value. In any test a value will differ from the mean by three standard deviations approximately $0.1 \%$ of the time. In the US, with approximately 30,000 confirmed cases per year, ${ }^{26}$ sampling the entire population would produce 30,000 true positives 
but approximately 300,000 false positives! Without a reasonable a priori likelihood of the disease, the ELISA is ten times as likely to be misleading as helpful. For this reason, testing should only be performed in a clinically appropriate setting. Specifically, there should be a reasonable likelihood of exposure to infected Ixodes ticks, and symptoms should be within the realm of disorders reasonably attributed to this infection.

\section{WHAT IS NERVOUS SYSTEM DISEASE?}

Virtually all the controversy surrounding the diagnosis of Lyme disease stems from one fundamental misconception: that a broad range of symptoms that, in fact, reflect either behavioural phenomena or physiological (i.e. nonstructural) changes in brain function are indicative of nervous system infection. Many patients with chronic illnesses develop depression - this does not mean that depression is caused by brain damage from that chronic illness. Epidemiologic studies have not shown depression to be more common in patients with Lyme disease than in any other chronic illness. ${ }^{27,28}$ Conversely, Lyme disease does not occur more frequently than expected by chance in any specific psychiatric disorder. ${ }^{29,30}$

Individuals with many inflammatory states - pneumonia, urinary tract infections, inflammatory bowel disease, lupus - describe fatigue, memory difficulty and difficulty concentrating - yet nobody would suggest these disorders are causing brain damage. This notwithstanding, some have suggested that symptoms of fatigue, difficulty concentrating, depression and so on, are themselves sufficient to make the diagnosis of Lyme disease. When such patients fail to respond to standard courses of antimicrobial therapy regimens that are almost invariably curative in patients with even severe nervous system infections - the possibility of an incorrect diagnosis is discarded in favour of postulating ever more non-evidence-based hypotheses for persistent, resistant infection.

Changes in behaviour and function arise for one of three reasons - neurological disease, psychiatric disease and physiological changes impacting brain function but due to systemic disease. Neurological disease reflects alteration in the structure of the nervous system - be it focal, such as in stroke, trauma or Parkinson's disease, or more diffuse, such as in meningitis, neuropathies or Alzheimer's. No such structural abnormalities have yet been identified in psychiatric disease, disorders that likely reflect biochemical and physiological changes in brain function but are not caused by loss of specific neuronal populations. In contrast, in many systemic disorders - hepatic or renal insufficiency, systemic infections as common as the flu, other inflammatory disorders - patients often experience impaired concentration and cognitive function, yet have no demonstrable damage to the nervous system.
TABLE 2 Neurological disorders in Lyme disease

\begin{tabular}{|l|l|l|}
\hline $\begin{array}{l}\text { Presumed } \\
\text { process }\end{array}$ & $\begin{array}{l}\text { Peripheral nervous } \\
\text { system }\end{array}$ & $\begin{array}{l}\text { Central nervous } \\
\text { system }\end{array}$ \\
\hline Diffuse neuro-inflammatory & Lymphocytic meningitis \\
\hline & \multicolumn{2}{|l|}{} \\
\hline Multifocal neuro-inflammatory \\
\hline & $\begin{array}{l}\text { Mononeuropathy } \\
\text { multiplex }\end{array}$ & $\begin{array}{l}\text { Myelitis (with } \\
\text { radiculopathy) }\end{array}$ \\
\hline & $\begin{array}{l}\text { Cranial neuropathy } \\
\text { (5-10\%) }\end{array}$ & $\begin{array}{l}\text { Encephalitis (very } \\
\text { rare) }\end{array}$ \\
\hline & Radiculopathy (?3-5\%) & \\
\hline & $\begin{array}{l}\text { Plexopathy (lumbo- } \\
\text { sacral, brachial) }\end{array}$ & $\begin{array}{l}\text { Confluent mono- } \\
\text { neuropathy multiplex }\end{array}$ \\
\hline \multicolumn{3}{|l}{ Non-neurological inflammatory } \\
\hline & \multicolumn{2}{|l}{\begin{tabular}{l} 
(common) \\
\hline
\end{tabular}}
\end{tabular}

This framework provides an appropriate context for a consideration of what constitutes nervous system Lyme disease (Table 2). The best-described disorders constitute the triad described initially in Europe by Garin and Bujadoux ${ }^{2}$ and then in the US by Reik ${ }^{31}$ and Pachner. ${ }^{32}$ Early in infection, patients develop lymphocytic meningitis, cranial neuritis and/or radiculoneuritis. The lymphocytic meningitis is, by itself, largely indistinguishable from viral meningitis. Algorithms ${ }^{33,34}$ that have been proposed to differentiate the two are largely dependent on cooccurring phenomena, such as cranial nerve palsies.

Since Lyme disease results from the bites of ticks that are inactive in cold weather, the seasonal incidence of Lyme and of enteroviral meningitis are similar. Onset of headache and other systemic symptoms may be somewhat less acute in Lyme disease than in viral meningitis, with onset bringing patients to medical attention after several days, rather than hours. Severity of headache and other symptoms in Lyme neuroborreliosis is highly variable, with only a weak correlation with the degree of cerebrospinal fluid (CSF) pleocytosis. An examination of CSF shows a lymphocytic pleocytosis, with counts typically of no more than 100 or 200 cells $/ \mathrm{mm}^{3}$. Protein is only modestly increased - typically no more than two to four times the upper limit of normal. Glucose is normal to minimally decreased. Somewhat unusual is a rather striking $B$ cell predominance in the CSF. In both Lyme disease and syphilis there is an unusually prominent and early increase in CSF concentration of $\mathrm{CXCLI} 3^{35}$ - a chemokine that is a very strong B cell attractant; the concentration of CSF B cells in these two spirochaetal infections is higher than in just about any other disorder. Presumably reflective of the disproportionate elevation in B cells, many patients particularly those symptomatic more than a few weeks - will have evident excess total IgG synthesis in the CSF 
and even oligoclonal bands. (This is reported more frequently in patients in Europe than in the US.)

The most common manifestation of nervous system infection in both Europe and the US is cranial nerve involvement - most often facial nerve palsy, which is reported in 5-8\% of early, untreated patients. The disorder itself is indistinguishable from Bell's palsy in other circumstances except that in Lyme disease it can be bilateral in up to $20-25 \%$ of affected individuals. Bilateral involvement occurs infrequently otherwise (occurring in sarcoidosis, Guillain-Barré syndrome and human immunodeficiency virus infection). Similarly, idiopathic Bell's palsy is otherwise quite uncommon in young children. It is important to consider this treatable cause of facial nerve palsy in appropriate contexts, but it is also important to realise that neuroborreliosis accounts for only about $25 \%$ of summertime facial nerve palsies in hyperendemic areas. ${ }^{36}$

Although many patients with Lyme-associated facial nerve palsies have co-occurring meningitis, others do not. Clinical and neurophysiologic evidence suggests that nerve involvement occurs in the peripheral portion of the nerve, not as a result of the meningitis, but rather due to a mononeuropathy multiplex. ${ }^{37,38}$

Although $80 \%$ of Lyme-associated cranial nerve palsies affect the facial nerve, others can be involved. Involvement of nerves to the extra-ocular muscles (III, IV, $\mathrm{VI}$ ) can cause diplopia. Involvement of the $V$ th nerve can cause hypoaesthesia or pain; VIIlth nerve involvement can result in hearing changes or vertigo. Optic nerve involvement (II; actually part of the central nervous system) occurs rarely if ever. ${ }^{39}$ Individual case reports describe lower cranial nerve deficits (IX to XII). ${ }^{42}$

The most commonly misdiagnosed disorder is what has been termed 'radiculoneuropathy', which probably occurs in up to $4-5 \%$ of untreated infected individuals. Patients typically have symptoms indistinguishable from a mechanical radiculopathy, such as that caused by an acute disc herniation. Pain is dermatomal in distribution, severe, and neuropathic in character - described as burning, stabbing, shock-like, debilitating and persistent. Pain can involve a limb or the trunk - the latter can be confused with a visceral process and patients are often extensively evaluated for intra-thoracic or intra-abdominal processes. In Europe, involvement is thought to occur most often in the limb that was the site of the tick bite, an association not described in the US. Although thought to be more common in European patients than in the US, the disorder is so under-recognised that it is very difficult to know its true incidence in either region.

As in Lyme-associated cranial neuropathies, patients with radiculopathy usually have an accompanying CSF pleocytosis. That notwithstanding, neurophysiological observations suggest that this radiculopathy, similarly, is actually part of a mononeuropathy multiplex. ${ }^{38}$ This pathophysiological construct is further reinforced by the observations that more typical mononeuropathies occur as well, as do brachial and lumbosacral plexopathies, suggesting a common mechanism for all forms of peripheral nerve involvement. Interestingly, all of these acute, localised forms of peripheral nerve involvement occur fairly early in infection (within months of initial infection). In patients who have had more longstanding infection (something seen only rarely in recent years) a more diffuse polyneuropathy can occur - with more typical signs and symptoms of distal sensorimotor loss. ${ }^{38,40}$ Neuro-physiological testing in these individuals again suggests that this represents a confluent mononeuropathy multiplex - the same underlying process but in more indolent form. Finally, the only good animal model of nervous system Lyme disease - the rhesus macaque monkey - is remarkable in that virtually all infected animals develop a mononeuropathy multiplex. ${ }^{41}$

In contrast to the peripheral nervous system, the central nervous system is involved - other than by meningitis - only rarely. A pseudotumour cerebri-like picture has been described in children. These children typically have had a CSF pleocytosis, an atypical finding in pseudotumour. However, the intracranial hypertension can lead to visual loss and must be managed, both with antimicrobials and with the same modalities used in idiopathic pseudotumour.

Particularly in Europe, patients with radicular symptoms not infrequently have spinal cord involvement at the affected level, with long track signs on examination and changes demonstrable on magnetic resonance imaging (MRI). Parenchymal brain involvement is extremely rare - estimated years ago to occur in about one patient per million population at risk per year. ${ }^{42}$ Now that patients are treated more aggressively early on, the incidence is undoubtedly even lower. These rare individuals develop focal neurological abnormalities, focal changes on brain MRI and inflammatory CSF. The process reflects a bacterial encephalitis and as such an inflammatory response in the CSF is virtually universal.

A useful technique in individuals with inflammatory CSF is measurement of local production of specific anti- $B$. burgdorferi antibodies in the CSF - referred to as intrathecal antibody production (ITAb) ${ }^{43-46}$ This approach is used in numerous other infections and can be performed by a number of different techniques. In all, the underlying principle is the determination of the proportion of immunoglobulin that is specific to the causative organism, comparing this proportion in CSF and serum. Since some IgG antibody crosses the blood-brain barrier, but infection leads to clonal proliferation of specific B cells in the CSF, patients with infection will have proportionally more specific immunoglobulin in the CSF. This determination requires measuring antibody in both CSF and blood and determining CSF positivity by showing proportionately more specific antibody in the CSF, not by comparing to normal values. 
The technique is highly specific, with cross-reactions occurring only in other spirochaetal infections, specifically neurosyphilis. However, since patients with neurosyphilis almost always have anti-reaginic antibodies (VDRL, RPR) these two infections are usually readily differentiated. The greater challenge is that apparent ITAb synthesis has been demonstrated to persist as long as 10 years after curative therapy. The other issue is that, although this approach is highly specific, sensitivity is difficult to ascertain in the absence of a gold standard diagnostic test. Estimates range from $50-95 \%$. The one setting in which sensitivity should approach $100 \%$ is patients with otherwise demonstrable intrathecal excess immunoglobulin production - patients with focal abnormalities on MRIs and increased lgG synthesis overall or oligoclonal bands. In such individuals, if the immune stimulation is due to a specific infection, the excess antibody that is present should be largely specific to the inciting organism.

The final entity to consider is 'Lyme encephalopathy'. Originally described in patients with longstanding active Lyme arthritis, ${ }^{47}$ this consisted of perceived cognitive slowing, memory difficulty and difficulty concentrating in the context of chronic inflammatory symptoms. Most of these patients had nothing to suggest central nervous system (CNS) inflammation - with normal CSF, MRI scans and non-focal neurological examinations. In many, formal neuropsychological examinations confirmed the patients' difficulties. Importantly, the concept was never that this disorder was unique to Lyme disease but rather that it was a particular example of the commonly observed 'toxic metabolic' encephalopathy seen in many inflammatory states - a model that might prove useful in learning about the pathophysiology of this very frequent phenomenon. Interpretation of this observation is further confounded by the fact that at any given time, a sizeable proportion of the general population experiences similar symptoms in the absence of any medical diagnosis - and these symptoms are significantly disabling in as many as $2 \%$ of the population. ${ }^{48}$

Unfortunately, some have concluded that the presence of this type of encephalopathy can lead to the "clinical diagnosis' of Lyme disease - even in the absence of likely exposure to ticks, more typical signs or symptoms or positive laboratory tests. In fact, these symptoms warrant neither a diagnosis of Lyme disease nor a diagnosis of any neurological disorder.

Despite normal brain MRI scans in most of these patients, some have used single photon emission computed tomography (SPECT) scanning in an effort to demonstrate abnormalities, and in turn have used SPECT evidence of regional brain hypometabolism as confirmatory evidence of Lyme disease. ${ }^{49}$ Unfortunately, SPECT scanning is not particularly reliable or specific, making such an approach highly questionable. In fact, studies using positron emission tomography (PET) scans, a more reliable measure of brain metabolism, show that areas of Lyme encephalitis are

\begin{tabular}{|c|c|c|}
\hline Disorder & Adults & Children \\
\hline \multirow{6}{*}{$\begin{array}{l}\text { Acute } \\
\text { neuroborreliosis } \\
\text { (meningitis, } \\
\text { radiculitis, } \\
\text { cranial neuritis) }\end{array}$} & $\begin{array}{l}\text { Ceftriaxone* } 2 \text { g/day } \\
\text { IV; } 2-4 \text { wk or }\end{array}$ & $75-100 \mathrm{mg} / \mathrm{kg} / \mathrm{day}$ \\
\hline & $\begin{array}{l}\text { Cefotaxime } 2 \mathrm{~g} \\
\text { 8-hourly IV; 2-4 wk } \\
\text { or }\end{array}$ & $\begin{array}{l}150-200 \mathrm{mg} / \\
\mathrm{kg} / \text { day in } 3-4 \\
\text { divided doses }\end{array}$ \\
\hline & $\begin{array}{l}\text { Penicillin, } 20-24 \text { million } \\
\text { units IV/day; } 2-4 \text { wk or }\end{array}$ & $\begin{array}{l}300,000 \text { units/ } \\
\mathrm{kg} / \text { day }\end{array}$ \\
\hline & $\begin{array}{l}\text { Probably doxycycline } \\
100 \mathrm{mg} \text { PO b.i.d. to } \\
\text { q.i.d. for } 3-4 \mathrm{wk}\end{array}$ & $\begin{array}{l}\geq 8 \mathrm{yr} \quad \mathrm{I}-2 \mathrm{mg} / \mathrm{kg} \\
\text { b.i.d. }\end{array}$ \\
\hline & $\begin{array}{l}\text { Possible alternatives: } \\
\text { Amoxicillin } 500 \text { mg } \\
\text { PO t.i.d.; } 21 \text { days or }\end{array}$ & $\begin{array}{l}50 \mathrm{mg} / \mathrm{kg} / \text { day in } \\
3 \text { divided doses }\end{array}$ \\
\hline & $\begin{array}{l}\text { Cefuroxime axetil } 500 \\
\text { mg PO b.i.d.; } 21 \text { days }\end{array}$ & $\begin{array}{l}150-200 \mathrm{mg} / \\
\mathrm{kg} / \text { day in } 3-4 \\
\text { divided doses }\end{array}$ \\
\hline Encephalomyelitis & $\begin{array}{l}\text { Ceftriaxone* or } \\
\text { cefotaxime or } \\
\text { penicillin IV } \\
\text { as above }\end{array}$ & \\
\hline $\begin{array}{l}\text { Chronic or } \\
\text { recurrent } \\
\text { neuroborreliosis } \\
\text { (e.g. treatment } \\
\text { failure after } 2 \mathrm{wk} \\
\text { of treatment) }\end{array}$ & $\begin{array}{l}\text { Ceftriaxone* or } \\
\text { cefotaxime IV } \\
\text { as above }\end{array}$ & \\
\hline
\end{tabular}

"Ceftriaxone should not be used late in pregnancy.

'Doxycycline should not be used in pregnant women or children under the age of eight years.

actually hyper-metabolic, a more plausible observation given the hypercellular inflammatory infiltrates in involved areas..$^{50}$ Although the mechanism of this encephalopathy - in Lyme or in other disorders - remains to be determined, several interesting observations may be relevant. A reasonable supposition would be that one or more soluble factors exist peripherally as part of the inflammatory response, are able to cross the blood-brain barrier, and then affect nervous system function. One such candidate molecule has been identified - quinolinic acid - which has been shown to be present in the serum and CSF of patients with a number of infectious disorders, ${ }^{51.52}$ including Lyme disease. What makes this molecule of particular interest is that it is known to activate the $\mathrm{N}$-methyl-D-aspartic acid (NMDA) receptor in the brain. The activation of this receptor can not only affect behaviour but, if excessive, can lead to neuronal death.

\section{TREATMENT}

Although some have focused on groups of patients who do not respond to standard treatment regimens, in the vast majority of cases this is likely due to inaccurate diagnosis. Borrelia burgdorferi is quite sensitive to betalactams and tetracyclines; no meaningful antimicrobial 
resistance has been observed. ${ }^{5}$ Treatment of early disease with simple oral regimens is highly effective. ${ }^{5,6,53}$ There is excellent evidence that, at least with European strains of Borrelia, oral doxycycline is as effective as highdose intravenous beta-lactams for Lyme meningitis, cranial neuritis and radiculoneuropathy. ${ }^{6,53}$ This is untested in the US, so parenteral treatment of such patients is commonplace but probably unnecessary. In those rare patients with demonstrable parenchymal involvement of the brain or spinal cord, intravenous regimens are appropriate, as they are in those uncommon patients who do not respond to oral regimens.

Currently recommended regimens are summarised in Table 3; although these were questioned by some, a recent review by an independent panel established by the Infectious Diseases Society of America confirmed that the evidence supporting these regimens is excellent and compelling. ${ }^{54}$ Similarly, the review committee reaffirmed the evidence-based consensus that prolonged antibiotic treatment beyond four weeks was generally of no benefit and potentially harmful.

\section{PATHOPHYSIOLOGY}

Although a great deal is known about this infection and the host response to it, the fundamental processes underlying nervous system involvement remain unclear..$^{55}$ Plausible mechanisms include active infiltration with spirochaetes, deposition of spirochaetal antigens with an inflammatory response, 'molecular mimicry' with a molecular similarity between spirochaete and host antigens resulting in a misdirected host immune response, and an exaggerated host response to the spirochaete.

At the most basic level, ongoing infection appears essential, as all peripheral and central nervous system manifestations respond - although not instantaneously - to antimicrobial therapy. This same observation would seem to argue against molecular mimicry, since such a

\section{REFERENCES}

I Afzelius A. Verhandlugen der dermatorischen Gesellschaft zu Stockholm. Arch Derm Syphiligr 1910; 101:404.

2 Garin C, Bujadoux A. Paralysie par les tiques. J Med Lyon 1922; 7I:765-7.

3 Burgdorfer W, Barbour AG, Hayes SF et al. Lyme disease: a tick borne spirochetosis? Science 1982; 216:1317-9. doi:10.1126/ science.7043737

4 Asbrink E, Hederstedt B, Hovmark A. The spirochetal etiology of acrodermatitis chronica atrophicans Herxheimer. Acta Derm Venereol 1984; 64:506-12.

5 Wormser GP, Dattwyler RJ, Shapiro ED et al. The clinical assessment, treatment, and prevention of Lyme disease, human granulocytic anaplasmosis, and babesiosis: clinical practice guidelines by the Infectious Diseases Society of America. Clin Infect Dis 2006; 43:1089-134. doi:10.1086/508667

6 Mygland A, Ljostad U, Fingerle $V$ et al. EFNS guidelines on the diagnosis and management of European Lyme neuroborreliosis. Eur J Neurol 2010; 17:8-16. doi:I0.1 I I I/j.|468-1331.2009.02862.x persistent immune response would presumably continue even after removal of the precipitating micro-organism. Several observations provide additional useful insights. Polymerase chain reaction studies indicate that spirochaetes enter the CNS early and frequently, although this may only lead to ongoing nervous system infection in a subset of patients. The CSF concentration of $\mathrm{CXCLI} 3$ climbs rapidly ${ }^{35}$ - before the serum concentration - indicating early immune activation resulting in a rapid and persisting proliferation of a $B$ cell response in the nervous system. The frequent presence of CSF oligoclonal bands and persisting intrathecal antibody production speak to prominent and persisting stimulation of the humoral immune response within the CNS. Peripheral nerve from both infected patients and experimentally infected rhesus macaque monkeys ${ }^{56}$ demonstrates prominent perivascular inflammation without evidence of vasculitis (no vessel wall necrosis), spirochaetes, spirochaetal antigens or DNA, or immune complexes. Borrelia burgdorferi bind to gangliosides and to glia, and can induce glial proliferation..$^{57,58}$ The best synthesis suggests that a small number of spirochaetes lodge in the nervous system and elicit a vigorous inflammatory response that produces most of the end-organ effects but subsides after eradication of the infection.

\section{SUMMARY/FUTURE DIRECTIONS}

Although Lyme disease has taken on almost mythological proportions, it is clear that this is a largely straightforward bacterial infection. Readily available diagnostic tools are as accurate as those used in most other illnesses, and straightforward therapeutic regimens are highly effective, even in most cases in which the nervous system is involved. Future research will need to focus on a better understanding of the pathophysiological mechanisms responsible for nervous system involvement - both to inform new therapeutic strategies in this infection and hopefully to provide insights into mechanisms underlying neurological abnormalities in other inflammatory and infectious diseases.

7 Steere AC, Malawista SE, Hardin JA et al. Erythema chronicum migrans and Lyme arthritis. The enlarging clinical spectrum. Ann Intern Med 1977; 86:685-98.

8 Benach JL, Bosler EM, Hanrahan JP et al. Spirochetes isolated from the blood of two patients with Lyme disease. N Engl J Med 1983; 308:740-2.

9 Steere AC, Grodzicki RL, Kornblatt AN et al. The spirochetal etiology of Lyme disease. N Engl J Med 1983; 308:733-40.

10 Bannwarth A. Chronische lymphocytare Meningitis, entzündliche Polyneuritis und 'Rheumatismus'. Arch Psychiatr Nervenkr 194I; I I 3:284-76. doi:I0.1007/BF02095652

II Hellerström S. Erythema chronicum migrans Afzelius with meningitis. Acta Derm Venereol (Stockh) 195I; 31:227-34.

12 Warshafsky S, Lee DH, Francois LK et al. Efficacy of antibiotic prophylaxis for the prevention of Lyme disease: an updated systematic review and meta-analysis. J Antimicrob Chemother 2010; 65: I 137-44. doi: 10.1093/jac/dkq097

I3 Nadelman RB, Nowakowski J, Fish D et al. Prophylaxis with singledose doxycycline for the prevention of Lyme disease after an 
Ixodes scapularis tick bite. N Engl J Med 200I; 345:79-84. doi:I0.1056/NEJM200I07/2345020 I

14 Guerra M,Walker E, Jones $\mathrm{C}$ et al. Predicting the risk of Lyme disease: habitat suitability for Ixodes scapularis in the north central United States. Emerg Infect Dis 2002; 8:289-97. doi:10.3201/eid0803.010166

15 Gerber MA, Shapiro ED, Burke GS et al. Lyme disease in children in southeastern Connecticut. N Engl J Med 1996; 335:1270-4. doi: I0.1056/NEJMI996/0243351703

16 Luft BJ, Steinman CR, Neimark HC et al. Invasion of the central nervous system by Borrelia burgdorferi in acute disseminated infection. JAMA 1992; 267:1364-7.

17 Nowakowski J, Schwartz I, Liveris D et al. Laboratory diagnostic techniques for patients with early Lyme disease associated with erythema migrans: a comparison of different techniques. Clin Infect Dis 200I; 33:2023-7. doi: I0.1086/324490

18 Dattwyler RJ,Volkman DJ, Luft BJ et al. Seronegative Lyme disease. Dissociation of specific T- and B-lymphocyte responses to Borrelia burgdorferi. N Engl J Med 1988; 319:144I-6.

19 Anon. Recommendations for test performance and interpretation from the Second National Conference on Serologic Diagnosis of Lyme Disease. MMWR Morb Mortal Wkly Rep 1995; 44:590-I.

20 Dressler F, Ackermann R, Steere AC. Antibody responses to the three genomic groups of Borrelia burgdorferi in European Lyme borreliosis. J Infect Dis 1994;169:313-8.

21 Hauser U, Lehnert G, Wilske B. Validity of interpretation criteria for standardized Western blots (immunoblots) for serodiagnosis of Lyme borreliosis based on sera collected throughout Europe.J Clin Microbiol 1999; 37:224I-7.

22 Brouqui P, Bacellar F, Baranton $G$ et al. Guidelines for the diagnosis of tick-borne bacterial diseases in Europe. Clin Microbiol Infect 2004; 10:1 108-32. doi:10.1III/j.1469-0691.2004.01019.x

23 Robertson J, Guy E, Andrews $\mathrm{N}$ et al. A European multicenter study of immunoblotting in serodiagnosis of lyme borreliosis.J Clin Microbiol 2000; 38:2097-102.

24 Philipp MT, Bowers LC, Fawcett PT et al. Antibody response to IR6, a conserved immunodominant region of the VIsE lipoprotein, wanes rapidly after antibiotic treatment of Borrelia burgdorferi infection in experimental animals and in humans. J Infect Dis 200I; 184:870-8. doi: 10.1086/323392

25 Bacon RM, Biggerstaff BJ, Schriefer ME et al. Serodiagnosis of Lyme disease by kinetic enzyme-linked immunosorbent assay using recombinant VIsEI or peptide antigens of Borrelia burgdorferi compared with 2-tiered testing using whole-cell lysates.J Infect Dis 2003; 187: I 187-99. doi: I0.1086/374395

26 Bacon RM, Kugeler KJ, Mead PS. Surveillance for Lyme disease United States, 1992-2006. MMWR Surveill Summ 2008; 57:I-9.

27 Kaplan RF, Meadows ME,Vincent LC et al. Memory impairment and depression in patients with Lyme encephalopathy: comparison with fibromyalgia and nonpsychotically depressed patients. Neurology 1992; 42: 1263-7.

28 Kaplan RF,Jones-Woodward L,Workman K et al. Neuropsychological deficits in Lyme disease patients with and without other evidence of central nervous system pathology. Appl Neuropsychol 1999; 6:3-II. doi:I0.I207/s I5324826an060I_I

29 Nadelman RB, Herman E,Wormser GP. Screening for Lyme disease in hospitalized psychiatric patients: prospective serosurvey in an endemic area. Mt Sinai J Med 1997; 64:409-12.

30 Grabe HJ,Spitzer C, Lüdemann J et al. No association of seropositivity for anti-Borrelia IgG antibody with mental and physical complaints. Nord J Psychiatry 2008; 62:386-91. doi:10.1080/08039480801984230

31 Reik L, Steere AC, Bartenhagen NH et al. Neurologic abnormalities of Lyme disease. Medicine (Baltimore) 1979; 58:28I-94. doi:10.1097/00005792-197907000-0000I

32 Pachner AR, Steere AC. Neurological findings of Lyme disease. Yale J Biol Med 1984; 57:48I-3.

33 Garro AC, Rutman M, Simonsen K et al. Prospective validation of a clinical prediction model for Lyme meningitis in children. Pediatrics 2009; I 23:e829-34. doi:10.1542/peds.2008-2048

34 Tuerlinckx D, Bodart E, Jamart J et al. Prediction of Lyme meningitis based on a logistic regression model using clinical and cerebrospinal fluid analysis: a European study. Pediatr Infect Dis / 2009; 28:394-7. doi:I0.1097/INF.0b013e31819If035

35 Rupprecht TA, Plate A,Adam M et al. The chemokine CXCLI 3 is a key regulator of $B$ cell recruitment to the cerebrospinal fluid in acute Lyme neuroborreliosis. I Neuroinflammation 2009; 6:42. doi: I 0.1 I 86/1 742-2094-6-42

36 Halperin IJ, Golightly M, Long Island Neuroborreliosis Collaborative Study Group. Lyme borreliosis in Bell's palsy. Neurology 1990; 40:342.

37 Halperin JJ. Facial nerve palsy associated with Lyme disease. Muscle Nerve 2003; 28:516-7. doi:10.1002/mus.10451

38 Halperin JJ, Luft BJ, Volkman DJ et al. Lyme neuroborreliosis peripheral nervous system manifestations. Brain 1990; I13:120721. doi: I0.1093/brain/II3.4.1207

39 Sibony P, Halperin J, Coyle PK et al. Reactive Lyme serology in patients with optic neuritis and papilledema. J Neuroophthalmol 2005; 25:7I-82. doi:I0. 1097/0I.WNO.0000166060.35366.70

40 Logigian EL, Steere AC. Clinical and electrophysiologic findings in chronic neuropathy of Lyme disease. Neurology 1992; 42:303-II.

4I England JD, Bohm RP, Roberts ED et al. Mononeuropathy multiplex in rhesus monkeys with chronic Lyme disease. Ann Neurol 1997; 41:375-84. doi: 10.1002/ana.410410313

42 Halperin JJ, Logigian EL, Finkel MF et al. Practice parameter for the diagnosis of patients with nervous system Lyme borreliosis (Lyme disease). Neurology 1996; 46:619-27.

43 Wilske B, Schierz G, Preac-Mursic V et al. Intrathecal production of specific antibodies against Borrelia burgdorferi in patients with lymphocytic meningoradiculitis. J Infect Dis 1986; 153:304-14.

44 Hansen K, Lebech A-M. Intrathecal synthesis of Borrelia burgdorferi specific immunoglobulin $G, A$ and $M$ in neuroborreliosis - an antibody capture assay. In: Fourth international conference on Lyme borreliosis. Stockholm: 1990. p. 144.

45 Halperin JJ,Volkman DJ,Wu P. Central nervous system abnormalities in Lyme neuroborreliosis. Neurology 1991; 41:157|-82.

46 Blanc F, Jaulhac B, Fleury $M$ et al. Relevance of the antibody index to diagnose Lyme neuroborreliosis among seropositive patients. Neurology 2007; 69:953-8. doi:I0.12I2/0I.wnl.0000269672.17807.e0

47 Halperin JJ, Krupp LB, Golightly MG et al. Lyme borreliosisassociated encephalopathy. Neurology 1990; 40:1340-3.

48 Luo N, Johnson J, Shaw J et al. Self-reported health status of the general adult U.S. population as assessed by the EQ-5D and Health Utilities Index. Med Care 2005; 43:1078-86. doi:10.1097/0I. mlr.0000I82493.57090.cl

49 Fallon BA, Das S, Plutchok IJ et al. Functional brain imaging and neuropsychological testing in Lyme disease. Clin Infect Dis 1997; 25 (Suppl I):S57-63. doi:10.1086/516175

50 Kalina P, Decker A, Kornel E et al. Lyme disease of the brainstem. Neuroradiology 2005; 47:903-7. doi:10.1007/s00234-005-1440-2

5 I Heyes MP, Rubinow D, Lane C et al. Cerebrospinal fluid quinolinic acid concentrations are increased in acquired immune deficiency syndrome. Ann Neurol 1989; 26:275-7. doi:10.1002/ana.410260215

52 Halperin J], Heyes MP. Neuroactive kynurenines in Lyme borreliosis. Neurology 1992; 42:43-50.

53 Halperin J], Shapiro ED, Logigian EL et al. Practice parameter: treatment of nervous system Lyme disease. Neurology 2007; 69:9|-102. doi: I0.12 I2/01.wnl.00002655/7.66976.28

54 Lantos PM, Charini WA, Medoff G et al. Final report of the Lyme disease review panel of the Infectious Diseases Society of America. Clin Infect Dis 2010; $51: 1-5$.

55 Rupprecht TA, Koedel U, Fingerle $\mathrm{V}$ et al. The pathogenesis of Lyme neuroborreliosis: from infection to inflammation. Mol Med 2008; | 4:205-12.

56 England JD, Bohm RP, Roberts ED et al. Lyme neuroborreliosis in the rhesus monkey. Semin Neurol 1997; 17:53-6. doi:10.1055/s-2008-1040913

57 Ramesh G, Borda JT, Dufour J et al. Interaction of the Lyme disease spirochete Borrelia burgdorferi with brain parenchyma elicits inflammatory mediators from glial cells as well as glial and neuronal apoptosis. Am J Pathol 2008; 173:14I5-27. doi:10.2353/ajpath.2008.080483

58 Ramesh G, Borda JT, Gill A et al. Possible role of glial cells in the onset and progression of Lyme neuroborreliosis.J Neuroinflammation 2009; 6:23. doi:10.1 I86/1742-2094-6-23 